\title{
Investigating sentence severity with judicial open data
}

\section{A case study on sentencing high-tech crime in the Dutch criminal justice system}

\author{
Pieter Hartel $^{1}$ (D) . Rolf van Wegberg ${ }^{1}$ - Mark van Staalduinen ${ }^{2}$ (iD
}

Accepted: 9 December 2021

(C) The Author(s) 2022

\begin{abstract}
Open data promotes transparency and accountability as everyone can analyse it. Law enforcement and the judiciary are increasingly making data available, to increase trust and confidence in the criminal justice system. Due to privacy legislation, judicial open data like court judgements - in Europe is usually anonymized. And even if the court judgement has been made public, the rest of the case file is usually not published. Therefore, the question arises to what extent criminological research into sentencing can make use of anonymized open data. We answer this question based on a case study in which we use the open data of the Dutch criminal justice system that is available on rechtspraak.nl. Over the period 2015-2020, we analysed sentencing in 25,366 court judgements and investigated the relationship between sentence severity and the offender's use of advanced Information and Communication Technology (ICT). The most important results are, firstly, that offenders who use advanced ICT are sentenced to longer custodial sentences compared to other offenders . Secondly, sentencing research with open data is found to be feasible.
\end{abstract}

Keywords Focal concerns $\cdot$ Cybercrime $\cdot$ Sentence severity $\cdot$ Open data Open source . Coding software

Pieter Hartel

Pieter.Hartel@ tudelft.nl

Rolf van Wegberg

R.S.vanwegberg@tudelft.nl

Mark van Staalduinen

Mark.vanStaalduinen@cflw.com

1 Delft University of Technology, Delft, The Netherlands

2 CFLW Cyber Strategies B.V., 's-Gravenzande, The Netherlands 


\section{Introduction}

In the Netherlands, a judge has considerable freedom in making sentencing decisions. There is a universal minimum of 1 day in prison. The maxima differ per offence, with a generic maximum of 30 years imprisonment and a life sentence for a handful of offences. There are guidelines (LOVS, 2020), but they are not binding. The judge should impose the sentence, taking into account the personal circumstances of the offender and the interests of society. Sentencing decisions are, therefore, mainly tailor-made. Hence, sentencing is a complex issue that is not necessarily addressed in the same way by all judges.

Through the ages, technology has changed our lives and, therefore, crime (Felson \& Eckert, 2019). ICT has become an intrinsic part of most crimes hence we ask ourselves: how do judges sentence high-tech crime? Do judges rely on experts to fill their knowledge gap? Are there sentencing guidelines they can follow and how do they deal with complex cases under the pressure of time?

In theory, the variance in sentencing can be explained by the bounded rationality model (Simon, 1955). After all, the judge has to make a rational decision in a limited time, with limited information and no technical - e.g. ICT - expertise. The judge is not a machine, and even experienced judges make quick, instinctive, and emotional decisions (Kahneman, 2011). The focal concerns theory (Hartley, 2014) tries to explain the variance in sentencing. The theory states that sentencing is based on three aspects: blameworthiness, dangerousness, and practical considerations. The type of crime and the impact on the victims mainly determine blameworthiness. In ICT cases, we would argue, that the skill of the offender relates to blameworthiness too. That is, an offender may be misusing ICT skills to commit crimes. The dangerousness is determined by the degree to which the judge believes that the offender will pose a threat to society after his release. Here, we argue again that a skilled offender can be seen as potentially dangerous by a judge.

Here, we apply the focal concerns theory to the Dutch penal system. For example, a maximum sentence has been set for each offence, which is an important part of blameworthiness. The legislator has also determined that the personal circumstances of the offender may influence the decision. For example, an offender who has a job, a home, and a partner is less likely to re-offend. This aspect of sentencing is related to dangerousness. The legislator has also determined that certain aspects may not be taken into account - e.g. sex, country of birth, and race. Related work listed in Table 1 has researched the extent to which such aspects have nevertheless been included in sentencing decisions.

We have not been able to find related work on focal concerns theory where ICT has been highlighted. In modern society computers and networks cannot be ignored. ICT also plays a role in crime (Raets \& Janssens, 2021) and, therefore, in court cases (Bijlenga \& Kleemans, 2018). Victims are threatened via social media (Montoya et al., 2013), phishing is the modern modus operandi of fraud (Leukfeldt, 2014), drug trafficking leverages the TOR network (Christin, 2013), and Bitcoins are used for extortion and ransomware (Connolly \& Wall, 2019). It seems plausible that an offender who has used a certain technology also has to have some level of knowledge or skills to handle that technology. For example, an offender who launders money with Bitcoins probably knows how to acquire Bitcoins, how to store them, and how one can launder them. The offender does not need to have in-depth knowledge of the mathematical basis of Bitcoins, but he must have at least a Bitcoin wallet and be able to deal with it.

We assume that not all judges know enough about ICT to make a rational decision on technically complex cases. That is why we are specifically interested in the use of ICT by the 


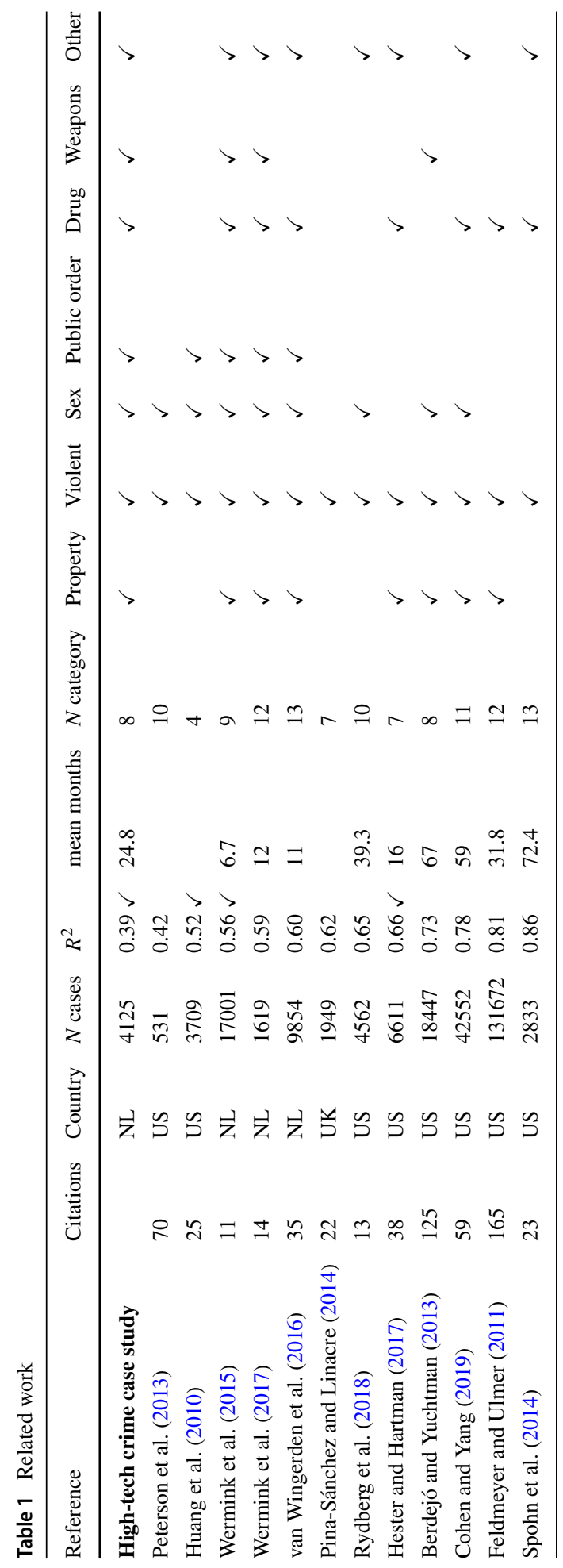


offender and the response of the judicial system. This makes it opportune to apply the focal concerns theory to the ICT knowledge or skills of both the offender and the prosecution. A possible technical lack of knowledge on the part of the judge will probably have the most influence on the second focal concern, the dangerousness. Could the offender be a technical expert who can be considered capable of realizing new threats? Can an offender with better technical knowledge hide from the police for longer? An expert can assist the court, but experts are scarce, and therefore practical considerations (third focal concern) are also relevant here. As far as we know, the role of ICT in focal concerns theory has not been investigated before. This is a gap in criminological research that we will address in a case study on sentencing high-tech crime in the Dutch criminal justice system (See Sections "Case Study: Background", "Case Study: Method", "Case Study: Results", "Case Study: Discussion". In the remainder of this section we establish a quality criterion for sentence severity research to be able to contrast the case study to related work.

\section{Related Work}

Most earlier work that studied sentencing severity is based on the Anglo-Saxon legal system - predominantly, the USA and the UK. This has specific aspects, such as plea-bargaining, presumptive sentences, and mandatory minima that do not exist in the Dutch legal system. As a result, American sentencing investigations cannot simply be compared with Dutch investigations. Therefore we have included several Dutch studies in the related work to be able to interpret our findings in the light of the national state-of-the-art.

It is common in sentencing research to predict the length of the custodial sentence with a linear regression on independent variables such as the age and sex of the offender, offence type, and prior record. The best regression models explain the largest percentage of the variance in sentence length. That is why we look at the $R^{2}$ to identify a baseline and contrast earlier work with ours.

To gain insight into the state-of-the-art in sentence severity research, Table 1 provides an overview of articles published in the last 10 years, in which a linear regression model predicts the length of detention. The articles included mainly differ in the choice of independent variables for the regression model and the population.

We first searched for journal articles with "sentence length" and $R^{2}$ in the full text using Google Scholar. This resulted in 167 articles, of which those with at least 10 citations were analysed further. We exclude articles that only mention the $R^{2}$ of a logistic regression, keeping only articles with a linear regression. Finally, we identified 28 articles that report the explained variance in sentence length. Of those 28 articles, we have coded the independent variables into 31 categories such as age, education, guideline departure, judge characteristics, and mandatory minimum. The columns of Table 1 show the reference, the number of citations on January 2021, the country from which the data originated, the $N$ of the OLS model, the $R^{2}$ reported, a checkmark when the $R^{2}$ was adjusted, the average number of months of incarceration, the number of categories of independent variables in the OLS model, and the offence types included in the study. The table is sorted by the $R^{2}$, from lowest to highest, where 16 papers with an $R^{2} \leq 0.35$ have been omitted to save space.

Wermink et al. (2015) provide an overview of the Dutch criminal justice system and the extent to which the theory of focal concerns applies to it. Both van Wingerden et al. (2016) and Wermink et al. (2017) study the influence of the personal circumstances of the offender on the sentencing. In a recent article, Light and Wermink (2021) investigate the influence of nationality on sentencing. The standard for Dutch sentencing research is set 
by van Wingerden et al. (2016), with an $R^{2}$ of 0.60 . None of the 28 articles focus on ICT knowledge or skills of offenders and judges.

Hadzhidimova and Payne (2019) have analysed press releases from the U.S. Department of Justice about $N=225$ cybercrime offenders who were not born in the US. Their main conclusion was that sentencing severity depends on the type of cybercrime. The influence of the application of advanced ICT on sentencing has therefore been studied to a limited extent, probably because this is a relatively new topic and because perhaps not all criminology researchers have sufficient affinity with ICT.

\section{Open Data}

Making court decisions available as open data promotes trust and confidence in the judiciary (Bargh et al., 2017). Lawyers and journalists can do their job better if they have a complete overview of case law. Offenders and victims have more insight into the cases in which they are involved or cases that are comparable. Policymakers can see the effect of their policies on court judgements.

We give three examples of judicial open datasets:

- In the Netherlands, approximately $5 \%$ of court decisions are available as anonymized open data via rechtspraak.nl. The selection criteria are also available on rechtspraak.nl. The most relevant criteria for our work are that court judgements are published in case of (a) a crime against someone's life, or (b) the maximum sentence is 4 years or more. Unfortunately, the reason for publishing a court judgement is not published.

- In England, non-anonymized essential information from some of the court judgements can be found in the commercial database of thelawpages.com. It is unknown which fraction of court judgements are available on thelawpages.com and which sampling method is used (Pina-Sánchez et al., 2019).

- In the interest of transparency and fairness of justice, the Supreme Court of the USA has ruled that everyone has the right to access criminal records. The open data of courtlistener.com consists of millions of rulings and verdicts (Cao et al., 2020).

Judicial open data is interesting for researchers because the data is immediately available, and lengthy application procedures are avoided. However, judicial open data is anonymized so that it cannot be linked to other data, like a trade register (van den Berg et al., 2017), or a population register (de Jong \& Dennison, 2017).

In the remainder of this article, we apply the methods and techniques of classic sentencing severity research to open data. The first research question we will answer is:

RQ1: To what extent are the limitations of open data a barrier to obtaining good results?

As a definition of quality, we use the $R^{2}$ of the linear regression between the independent variables and the length of the custodial sentence. To compare the results of the case study with the parameters of related research, we have already included the results of the case study in Table 1, entry High-tech crime case study.

Based on the focal concerns theory, we pose a second research question:

RQ2: To what extent do offenders in high-tech crime cases receive a more severe sentence than offenders in low-tech cases? 
After the Background, Method, Results, and Discussion of the case study, we conclude the article with Conclusions and Policy Recommendations.

\section{Case Study: Background}

We define high-tech crime as a type of crime in which the offender has used advanced ICT, such as malware, BitCoins, or a PGP phone. Crime where standard applications of ICT, such as email, online banking, and online shopping are used, is low-tech crime.

High-tech crime is a phenomenon that has developed over the past 10 years. Offenders have increasingly made use of advanced techniques. In 2012, for example, the first hightech criminal case in the Netherlands was published on rechtspraak.nl, but in 2020 there were 243 published high-tech cases.

In the Netherlands, there are several articles in the Penal code that are indicative of cybercrime, such as 138ab (Hacking), 139d (Eavesdropping), and 350d (Misuse of passwords). Unfortunately, these articles of law do not distinguish between standard ICT and advanced ICT. That is why we have chosen to search the court judgements for words and concepts that are characteristic of high-tech crime. For example, is the word Bitcoin used in the court judgement? Or has the judiciary engaged a technical expert from the Netherlands Forensic Institute (NFI), the Maastricht Forensic Institute (TMFI), or the Netherlands Organisation for Applied Scientific Research (TNO)?

To understand and appreciate the technical aspects of high-tech criminal cases, the police and judicial authorities have also had to study ICT in recent years. Where initially little knowledge of high-tech crime was available, specialist teams have now emerged, such as the Team High-Tech Crime (THTC) of the national police, and the cyber chamber of the court in The Hague.

When committing a high-tech offence, at least one of the offenders is assumed to have relevant ICT skills. Police and judicial authorities will therefore also need relevant knowledge when dealing with such a high-tech case. For example, the judge may rule that the offender in a high-tech case poses a greater danger to society than an offender without advanced ICT skills. Or a judge who is not sufficiently familiar with the technical aspects of the case could be more cautious than usual. The judge's considerations about the dangerousness of the offender may therefore be related to the technology.

One of the main uses of ICT is in automating manual processes. Since crime is a process, it can be automated as well. For example, with little effort, an offender may be able to reach millions of victims with a large-scale phishing campaign. ICT can increase the scale of crime, and thereby increase the blameworthiness of the offender. This further motivates the second research question.

The court judgements that are available as open data on rechtspraak.nl were anonymized to guarantee the privacy of the offender. Names, residential, IP and web addresses are replaced by pseudonyms that indicate roles, such as [offender], [co-offender 2], or [web address 3]. Some courts even omit the offender's year of birth. A court judgement is usually accompanied by a summary and the indictment. Police case files, reports from the probation service, and other judicial documentation are not part of the open data. 


\section{Case Study: Method}

Table 2 shows the total number of criminal court judgements in the years 2015 to 2020 (Meijer et al., 2021, Table 6.1). The total number of criminal court judgements in the period 2015 to 2020 is 503,955 . In the same period, 49,790 criminal court judgements were published as open data by the Dutch district courts (courts of first instance). Of these court judgements, 23,186 contained only metadata, and 1,238 concern minors. Metadata is data about data. The metadata of judgements basically consist of the name of the court, the date of sentencing, the case number, and a brief summary of the judgement. Metadata does not contain sufficient information for sentencing research hence we omit incomplete court judgements. We also omit all court judgements where the offender is minor because they are sentenced under a different regime than adults. The total number of complete court judgements with an adult offender is 25,366 , or about $5 \%$ of the national total.

We analyse the obtained criminal court judgements in two ways:

1. A linear regression is used to find the relationship between the sentence length and relevant information about the offender, the offence, and the judiciary.

2. Cohen's kappa is calculated to investigate the reliability of the coding.

\section{The Coding}

A court judgement is a standardized document according to the PROMIS model (van den Hoven, 2011), in which not only the decision but also the relevant details of the offender, the offence, and the police investigation are presented.

Coding thousands of court judgements is time-consuming. But because a court judgement has a standard structure, it is in principle possible to code a court judgement with an appropriate computer program. During the development of the program, we discovered 40 problems in the public data of rechtspraak.nl, such as:

- We have found court judgements that are not completely anonymized.

- The legal basis is unclear in some court judgements. For example, the court judgement ECLI:NL:RBROT:2018:3004 mentions a non-existent article (10310): Having regard to articles 14a, 14b, ,, 36f, 57, 285, 10310, 311312 and 417bis of the Penal code and Article 11 of the Opium Act.

- The amount of fines, and the length of time periods are sometimes noted inconsistently. For example, sentences the offender to a term of imprisonment of 35 (thirty) months (ECLI:NL:RBROT:2018:1383).

Table 2 Total number of criminal cases processed by Dutch district courts

\begin{tabular}{lllllllll}
\hline & 2015 & 2016 & 2017 & 2018 & 2019 & 2020 & Total & $\%$ \\
\hline Adult men & 86,630 & 77,200 & 75,945 & 72,505 & 70,420 & 54,920 & 437,620 & 86.8 \\
Adult women & 13,010 & 11,350 & 11,015 & 9,970 & 9,370 & 6,520 & 61,235 & 12.2 \\
Other & 955 & 925 & 875 & 840 & 920 & 585 & 5,100 & 1.0 \\
Total & 100,595 & 89,475 & 87,835 & 83,315 & 80,710 & 62,025 & 503,955 & 100.0 \\
\hline
\end{tabular}


These errors have been reported to the authorities.

\section{The Data}

Our program coded the sentencing decision of 24,994 (98.6\%) court judgements. The distribution of the type of sentence is measure (e.g., compulsory treatment): $2.8 \%$, custodial sentence: $54.8 \%$, community service: $10.2 \%$, fine: $5.8 \%$, acquittal: $10.2 \%$, procedural court judgements (such as a ruling on extradition): $14.7 \%$. In $1.4 \%$ the sentencing decision could not be automatically coded. Manual analysis of a random sample of these judgements has shown that these are mainly procedural court judgements.

For 20,227 (79.7\%) court judgements, the program was able to code the offences for which the offender was convicted. Of the remaining $20.3 \%$ court judgements, the coding program did not find the legal basis (Wettelijke voorschriften), mainly because these are usually not mentioned if the offender is acquitted, or in procedural cases.

The top half of Table 3 shows the national statistics of court judgements for adults (Meijer et al., 2021, Table 6.2 minus Table 6.12). The bottom half of Table 3 shows the statistics of the court judgements for adults from the open dataset. All offences are classified using the standard crime classification of Statistics Netherlands cbs.nl, where the offence with the maximum sentence determines the classification of a judgement. The open dataset contains considerably more violent crime (31.6\%) than the national data $(19.4 \%)$, which is consistent with the publication criteria of the open data (see "Open Data").

Table 3 A comparison of the main type of offence per year

\begin{tabular}{|c|c|c|c|c|c|c|c|c|}
\hline Offence type & 2015 & 2016 & 2017 & 2018 & 2019 & 2020 & Total & $\%$ \\
\hline \multicolumn{9}{|c|}{ National statistics for adults } \\
\hline Property offences & 36,595 & 34,745 & 32,970 & 30,265 & 29,440 & 21,880 & 185,895 & 36.9 \\
\hline Violent offences & 20,250 & 18,405 & 16,830 & 15,440 & 14,570 & 12,435 & 97,930 & 19.4 \\
\hline Public order & 9,835 & 9,115 & 8,600 & 7,820 & 7,340 & 5,750 & 48,460 & 9.6 \\
\hline Other Penal code & 2,670 & 2,485 & 2,035 & 1,835 & 1,740 & 1,340 & 12,105 & 2.4 \\
\hline Road traffic & 17,945 & 12,480 & 14,110 & 14,975 & 15,905 & 12,000 & 87,415 & 17.3 \\
\hline Drugs related & 6,580 & 6,685 & 6,495 & 6,165 & 5,685 & 4,255 & 35,865 & 7.1 \\
\hline Weapons related & 1,335 & 1,195 & 1,050 & 1,035 & 1,000 & 770 & 6,385 & 1.3 \\
\hline Other criminal & 5,400 & 4,375 & 5,745 & 5,785 & 5,060 & 3,610 & 29,975 & 6.0 \\
\hline Total & 100,610 & 89,485 & 87,835 & 83,320 & 80,740 & 62,040 & 504,030 & 100.0 \\
\hline \multicolumn{9}{|c|}{ Open data statistics for adults } \\
\hline Property offences & 801 & 675 & 996 & 1,101 & 1,101 & 975 & 5,649 & 27.9 \\
\hline Violent offences & 912 & 765 & 1,106 & 1,255 & 1,214 & 1,131 & 6,383 & 31.6 \\
\hline Public order & 228 & 249 & 388 & 388 & 370 & 342 & 1,965 & 9.7 \\
\hline Other Penal code & 81 & 127 & 131 & 141 & 164 & 150 & 794 & 3.9 \\
\hline Road traffic & 147 & 90 & 153 & 158 & 147 & 180 & 875 & 4.3 \\
\hline Drugs related & 304 & 265 & 405 & 444 & 518 & 515 & 2,451 & 12.1 \\
\hline Weapons related & 81 & 58 & 93 & 110 & 149 & 132 & 623 & 3.1 \\
\hline Other criminal & 175 & 187 & 264 & 281 & 333 & 247 & 1,487 & 7.4 \\
\hline Total & 2,729 & 2,416 & 3,536 & 3,878 & 3,996 & 3,672 & 20,227 & 100.0 \\
\hline
\end{tabular}




\section{Hierarchical Linear Modelling (HLM)}

We ran a hierarchical linear regression to predict the length of the incarceration. The hierarchy consists of three levels:

1. The first model contains the maximum sentence for the offence, and the dummy-coded set of offences for which the offender is convicted. This level corresponds to the first focal concern, blameworthiness.

2. The second model also contains the variables that relate to trial, such as whether sentencing guidelines were consulted, and whether the judiciary has enlisted the services of technical experts. This level corresponds to the third focal concern, the practical matters (Crow \& Bales, 2006).

3. The third model contains the variables related to the offender, such as sex, country of birth, age, prior record, and technical skills. This level corresponds to the second focal concern, the dangerousness.

We use factor analysis to determine whether there are latent variables that better explain the variance in sentencing than the manifest variables. We also look for interaction effects, to rule out that certain independent variables influence the effect of other independent variables on sentencing (Maddan et al., 2012; Ulmer \& Johnson, 2004).

\section{Variables}

The program automatically coded the variables listed below for the 25,366 court judgements. We first describe three categories of independent variables, followed by the dependent variable. We use ECLI:NL:RBROT:2018:6152 to illustrate how we coded the judgements. As far as we know, this is the first published ransom ware case in the Netherlands.

Offence-Related Independent Variables To determine the offence, we search the legal basis section (in the example case "11 Toepasselijke wettelijke voorschriften") and encode all listed laws and articles (here "9, 14a, 14b, 14c, 22c, 22d, 33, 33a, 36f, 45, 47, 57, 138a/b, 317 en 350a van het Wetboek van Strafrecht"). We then look up the articles of law in the relevant code to find out for which crimes the accused is convicted (here "Property offence", "Public order offence"). Hence the number of offences for which the offender is convicted in this case is 2 .

- Property offence, Violent offence, Public order offence, Other Penal code offence, Road traffic offence, Drugs-related offence, Weapons-related offence, and Other criminal offence: $0=$ no, 1 = yes. These variables represent the offence type, according to the standard crime categories of Statistics Netherlands cbs.nl. Since an offender can be convicted of more than one offence, we have dummy-coded the offence with the longest maximum sentence.

- Number of offences: 0 to 8

- Maximum prison months We have calculated the maximum length of imprisonment by looking up the relevant articles in the Penal Code as mentioned in the legal basis in the court judgement. With one exception, we have omitted the articles from Book One of the Penal Code because these articles typically indicate the framework within which the sentences in Book Two must be interpreted. The exception is that in some cases no other articles are mentioned than from Book One, for example, money-laundering 
convictions based on article $36 \mathrm{f}$ Book One. In that case, we took the maximum from Book One. We have not differentiated between different custodial sentences, such as involuntary commitment, imprisonment, and military detention. For life sentences, we have taken the legal maximum of 360 months (Crow \& Bales, 2006; Patrick \& Marsh, 2011). This variable is not normally distributed. Therefore, we dummy-coded the maximum — in months - as follows: 71 and shorter, 72-95, 96-107, 108-119 (reference), 120-143, 144-179, 180-215, and 216 and longer. These categories were chosen to achieve an optimal balance in the number of cases in each category. The smallest category 216 and longer holds $9.2 \%$ of the cases, and the largest category 144-179 has $16.6 \%$ of the cases.

Prosecution-Related Independent Variables To determine whether a guideline has been consulted, we scan the entire judgement for words such as "LOVS", "orientatiepunten" and numbers of guidelines from the Public Prosecution Service such as "2018R001".

- Have guidelines been mentioned $(0=$ no, $1=$ yes $)$ If the judgement mentions the LOVS guidelines (LOVS, 2020), or specific guidelines of the Public Prosecution Service, we assume that the court has taken these into account. Otherwise, we assume that no guidelines were consulted.

- Has prosecution special expertise $(0=$ no, $1=$ yes $)$ To determine whether the police and the judiciary had deployed special expertise, we checked whether organizations such as NFI, TMFI, or TNO were mentioned in the court judgement or whether an expert witness was mentioned in the court judgement. We have not taken into account the area of expertise of the specialists, which might include ICT, but also firearms, DNA, and drugs analysis. In the absence of such a mention, we assume that no special expertise has been deployed.

Offender-Related Independent Variables To determine that we are dealing with a hightech case, we search the entire judgement for relevant terms (in the example case "malware" $(27 x)$, "bitcoin" $(14 x)$, "ransom ware" $(5 x)$, and "hacked server" (1x). In principle, it is possible that the offender himself has no knowledge of technology, but his co-offenders do. We checked several judgements manually but found no evidence of this.

- Age at sentencing The age is the difference between the year of birth and the year the sentence was pronounced. In some cases, this is a few years later than the age at the time of the offence because the judicial process sometimes takes years. Unfortunately, the year of birth is often omitted in open data. We dummy-coded the age into the same five categories as van Wingerden et al. (2016): 18-20, 21-30 (reference), 31-40, 41-50, and 51 and older.

- Is born abroad ( $0=$ no, $1=$ yes) If the offender was born abroad this is usually mentioned in the judgement. We, therefore, assume that the offender was born in the Netherlands unless it is explicitly stated that he/she was born elsewhere.

- Is female offender $(0=$ no, $1=$ yes $)$ The sex of the offender is not explicitly stated in the court judgement, but sometimes it is stated in the accompanying summary. If the court judgement or summary contains text fragments such as her co-offender, then the offender is deemed to be female, otherwise, we assume it is a man. This is consistent with the observation that most offenders are male.

- Is repeat offender $(0=$ no, $1=$ yes $)$ Some court judgements state explicitly whether the offender has been in contact with the police and the judicial authorities before. 
- Has multiple victims $(0=$ no, $1=$ yes $)$ As with the offenders, the victims are represented by pseudonyms, e.g. [victim 3]. From this, it can be deduced how many victims there were.

- Has offender basic skills $(0=$ no, $1=$ yes $)$ The coding program searches the court judgements for ICT-related standard terms such as Internet, $W W W$, and online. When we find one or more of those words, we assume that the offender has basic cyber skills. If we do not find any of those words, we assume that the offender has no demonstrable cyber skills.

- Has offender special skills ( $0=$ no, $1=$ yes) We also look for specialist concepts such as Bitcoin, TOR network, and Ransomware as evidence that the offender has more than just basic skills. If we cannot find any of these words, we assume that the offender has no demonstrable special skills. To avoid correlation between independent variables, we set Has offender basic skills to 0 if there are special skills.

Dependent Variable To determine the length of the prison sentence, we look for textual passages in the court judgement in which the decision is described (in the example case " 13 Beslissing"). In that section we look for the text fragment where the accused is sentenced ("veroordeelt de verdachte tot") and then locate the sentence (in the example randomware case "een gevangenisstraf voor de duur van 2 (twee) jaren"). The coding takes only the sentence length and ignores any measures that have been imposed in addition to a prison sentence.

- Prison months (logged) We did not take into account deductions for pre-trial custody or suspended sentences, and in the same way, as for the maximum we converted everything into months (= 30 days). This variable is also not normally distributed, but after a $\log$ transformation, a visual inspection of the Normal Q-Q plots showed that the transformed variable is distributed more or less normally.

\section{Reliability}

To check the reliability of the automatic coding, we manually checked the coding in a stratified random sample of 275 court judgements. That is about $1 \%$ of all complete court judgements. Because courts do not necessarily record judgements in the same way - for example, the Rotterdam District Court started an experiment in 2019 to make some court judgements more accessible — the 11 district courts form the first stratum. We also expect the wording of the judgements to change over time, and therefore take the years 2015-2020 as the second stratum. The stratification ensures that the distribution of the courts and the year of pronouncing the sentence in the random sample is the same as in the total collection of published court judgements. We calculate both the accuracy of the coding, as usual in the technical sciences, as well as Cohen's kappa, which is more common in the social sciences. We then manually checked coded information of all the court judgements in the sample: the age of the offender, the decision, and the legal basis of the decision.

- A true positive is when the coding program found the correct coding.

- A false positive arises if the coding by the program is wrong.

- If the program does not find any coding, while the relevant information is present, a false negative occurs.

- If the information is missing, and the coding program noted this, we have a true negative. 


\section{Case Study: Results}

We have found indications that, on average, high-tech crime leads to longer sentences. The automatic coding is reliable.

\section{Descriptive Statistics}

Tables 4 and 5 give the descriptive statistics of all variables. All dependent variables except one are more or less constant over time. The exception is the percentage of offenders with special ICT skills which, as can be expected, is steadily growing, from 2015: $1.6 \%, 2016$ : 2.4\%, 2017: $2.9 \%, 2018: 3.9 \%$, to $2019: 4.6 \%, 2020: 5.2 \%$.

\section{Regression: High-tech Crime Leads to a Significantly Longer Sentence}

We have verified that the assumptions of the linear regression analysis on the independence of residuals, linear relationships, homoscedasticity, and multicollinearity were met. There were 59 outliers with a sentence of, on average, 3.6 days whose residuals differed more from the predicted value than three standard deviations. In 47 cases, a short prison sentence was imposed in addition to community service to comply with article $22 \mathrm{~b}$ of the Penal code. In 2 cases, the offender was partially excused by insanity defence and sentenced to a short prison sentence and a treatment. In the remaining 10 cases the judge imposed a mild sentence. The outliers represent correctly coded judgements and were therefore kept in the dataset.

Table 6 shows that the Model 3 predicts the length of the custodial sentence in a statistically significant manner, $F(27,4646)=111.85, p<0.0005$, adjusted $R^{2}=0.39$. Most independent variables contribute significantly to the result.

Table 6 shows that most of the variance in sentencing is explained by Model 1. Models 2 and 3 each explain a small proportion of the variance. This means that the sentencing decision depends mostly on the offence, as required by law.

Model 3 mainly confirms what we expect about the relationship between the length of the custodial sentence and the independent variables. Since the independent variable is logged the coefficient $\mathrm{B}$ must be exponentiated before the value can be interpreted. We give a few examples:

- The most serious category of offences leads on average to a 3 times longer custodial sentence than an offence with the maximum sentence in the reference category (108119 months), because for model 3 we have the following: $\exp (B)=\exp (1.10)=$ 3.00 .

- All offences lead to shorter sentences than an offence in the reference category (violent offences).

Table 4 Descriptive statistics of ratio-scale variables

\begin{tabular}{llllll}
\hline Scale variable & $N$ & Minimum & Maximum & Mean & Std. Deviation \\
\hline Age at sentencing & 16772 & 18 & 90 & 37.91 & 13.23 \\
Number of offences & 20227 & 1 & 6 & 1.41 & 0.70 \\
Maximum prison months & 19527 & 0.47 & 360 & 129.98 & 79.07 \\
Prison months & 14406 & 0.03 & 360 & 24.79 & 36.03 \\
\hline
\end{tabular}


Table 5 Descriptive statistics dichotomous variables $(N=25,366)$

\begin{tabular}{|c|c|c|}
\hline Dichotomous variable & Frequency & Percent \\
\hline \multicolumn{3}{|l|}{ Maximum prison months } \\
\hline$\leq 71$ & 2,592 & $10.2 \%$ \\
\hline $72-95$ & 2,809 & $11.1 \%$ \\
\hline $96-107$ & 2,229 & $8.8 \%$ \\
\hline $108-119$ & 2,119 & $8.4 \%$ \\
\hline $120-143$ & 1,966 & $7.8 \%$ \\
\hline $144-179$ & 3,242 & $12.8 \%$ \\
\hline $180-215$ & 2,772 & $10.9 \%$ \\
\hline$\geq 216$ & 1,798 & $7.1 \%$ \\
\hline \multicolumn{3}{|l|}{ Type of offence } \\
\hline Property offence & 5,649 & $22.3 \%$ \\
\hline Violent offence & 6,383 & $25.2 \%$ \\
\hline Public order offence & 1,965 & $7.7 \%$ \\
\hline Other Penal code offence & 794 & $3.1 \%$ \\
\hline Road traffic offence & 875 & $3.4 \%$ \\
\hline Drugs-related offence & 2,451 & $9.7 \%$ \\
\hline Weapons-related offence & 623 & $2.5 \%$ \\
\hline Other criminal offence & 1,487 & $5.9 \%$ \\
\hline Number of offences & 20,227 & $79.7 \%$ \\
\hline Have guidelines been mentioned & 6,090 & $24.0 \%$ \\
\hline Has prosecution special expertise & 7,429 & $29.3 \%$ \\
\hline \multicolumn{3}{|l|}{ Age at sentencing } \\
\hline $18-20$ & 779 & $3.1 \%$ \\
\hline $21-30$ & 5,249 & $20.7 \%$ \\
\hline $31-40$ & 4,288 & $16.9 \%$ \\
\hline $41-50$ & 3,250 & $12.8 \%$ \\
\hline$\geq 51$ & 3,206 & $12.6 \%$ \\
\hline Is born abroad & 4,749 & $18.7 \%$ \\
\hline Is female offender & 2,042 & $8.1 \%$ \\
\hline Is repeat offender & 7,238 & $28.5 \%$ \\
\hline Has multiple victims & 5,917 & $23.3 \%$ \\
\hline Has offender basic skills & 12,160 & $47.9 \%$ \\
\hline Has offender special skills & 911 & $3.6 \%$ \\
\hline
\end{tabular}

- For each additional offence being committed, the sentence length is increased, on average, by $10 \%$.

- If the judgement mentions guidelines the sentence is, on average, $11 \%$ longer than in case guidelines have not been mentioned.

- If the prosecution has engaged the services of experts, the sentence is, on average, $78 \%$ longer than sentences where specialists have not been involved.

- The oldest offenders, on average, receive a $48 \%$ longer sentence than offenders in the reference age group (21-30). 
Table 6 Unstandardized coefficients of the three models for LN (sentence length )

\begin{tabular}{|c|c|c|c|c|c|c|}
\hline & $\begin{array}{l}\text { Model } 1 \\
\text { (offence) }\end{array}$ & & $\begin{array}{l}\text { Model } 2 \\
\text { (prosecution) }\end{array}$ & & $\begin{array}{l}\text { Model } 3 \\
\text { (offender) }\end{array}$ & \\
\hline Independent variable & B & S.E. & B & S.E. & $\mathrm{B}$ & S.E. \\
\hline (Constant) & $2.05 * * *$ & 0.08 & $1.83 * * *$ & 0.07 & $1.49 * * *$ & 0.08 \\
\hline \multicolumn{7}{|c|}{ Maximum prison months (108-119 ref.) } \\
\hline$\leq 71$ & $-0.70 * * *$ & 0.08 & $-0.63 * * *$ & 0.08 & $-0.75 * * *$ & 0.08 \\
\hline $72-95$ & $-0.80 * * *$ & 0.08 & $-0.71 * * *$ & 0.08 & $-0.82 * * *$ & 0.08 \\
\hline $96-107$ & $-0.25 * *$ & 0.09 & $-0.29 * *$ & 0.09 & $-0.31 * * *$ & 0.09 \\
\hline $120-143$ & n.s. & & n.s. & & n.s. & \\
\hline $144-179$ & $0.51 * * *$ & 0.09 & $0.46 * * *$ & 0.09 & $0.44 * * *$ & 0.09 \\
\hline $180-215$ & $1.12 * * *$ & 0.06 & $1.05 * * *$ & 0.06 & $1.08 * * *$ & 0.06 \\
\hline$\geq 216$ & $1.35 * * *$ & 0.08 & $1.20 * * *$ & 0.08 & $1.10 * * *$ & 0.08 \\
\hline \multicolumn{7}{|l|}{ Type of offence (Violent ref.) } \\
\hline Property offence & & n.s. & n.s. & & $-0.12 *$ & 0.05 \\
\hline Public order offence & $-0.81 * * *$ & 0.07 & $-0.76 * * *$ & 0.07 & $-0.77 * * *$ & 0.07 \\
\hline Other Penal code offence & $-0.58 *$ & 0.26 & $-0.50^{*}$ & 0.25 & $-0.53^{*}$ & 0.25 \\
\hline Road traffic offence & n.s. & & $-0.32 * *$ & 0.12 & $-0.29 *$ & 0.12 \\
\hline Drugs-related offence & $-0.62 * * *$ & 0.12 & $-0.77 * * *$ & 0.11 & $-0.75^{* * *}$ & 0.11 \\
\hline Weapons-related offence & n.s. & & n.s. & & n.s. & \\
\hline Other criminal offence & n.s. & & n.s. & & n.s. & \\
\hline Number of offences & $0.17 * * *$ & 0.02 & $0.15^{* * *}$ & 0.02 & $0.10 * * *$ & 0.02 \\
\hline Have guidelines been mentioned & & & $0.08 *$ & 0.04 & $0.11 * *$ & 0.04 \\
\hline Has prosecution special expertise & & & $0.63 * * *$ & 0.03 & $0.58 * * *$ & 0.04 \\
\hline \multicolumn{7}{|l|}{ Age at sentencing ( $21-30$ ref.) } \\
\hline $18-20$ & & & & & n.s. & \\
\hline $31-40$ & & & & & $0.22 * * *$ & 0.04 \\
\hline $41-50$ & & & & & $0.31 * * *$ & 0.05 \\
\hline 51 and older & & & & & $0.39 * * *$ & 0.05 \\
\hline Is born abroad & & & & & n.s. & \\
\hline Is female offender & & & & & n.s. & \\
\hline Is repeat offender & & & & & $0.11 * *$ & 0.03 \\
\hline Has multiple victims & & & & & $0.28 * * *$ & 0.03 \\
\hline Has offender basic skills & & & & & $0.15^{* * *}$ & 0.04 \\
\hline Has offender special skills & & & & & $0.67 * * *$ & 0.10 \\
\hline Adjusted $R^{2}$ & 0.31 & & 0.36 & & 0.39 & \\
\hline \multicolumn{3}{|c|}{ Significance: $* p<0.05, * * p<0.01, * * * p<0.001$} & \multicolumn{4}{|c|}{$N=4674$ (Valid listwise $)$} \\
\hline
\end{tabular}

- Repeat offenders receive, on average, a 12\% longer sentence than first-time offenders.

- Offenders with special ICT skills receive, on average, a 95\% longer custodial sentence than offenders without special skills.

We analysed a fourth model with the year of sentencing as an extra independent variable but found no significant changes to the model parameters. 
Factor analysis showed that the correlation between the manifest variables was always smaller than 0.25 . This makes it unlikely that there are latent factors that provide a better explanation for the variance in sentencing than the manifest variables.

We also investigated possible interaction effects. There is a possible interaction between Maximum prison months and Has prosecution special expertise because for the most serious offences the court may more often call in the expertise of specialists. There is also a possible interaction between Type of offence and Has offender special skills because special skills may be more useful for some offences (e.g. fraud) than for others (e.g. robbery). The change in $R^{2}$ due to these two interactions was found to be significant but small $(<0.004)$.

Finally, there is also possible interaction between Age at sentencing and Is repeat offender because repeat offenders are usually older than first offenders. The change in $R^{2}$ due to this last interaction was not significant.

\section{Cohen's Kappa: High Reliability of the Automatic Encoding}

It is common for multiple coders to compare their results and adjust them to an agreed coding scheme. In that case, the reliability of the coding before and after the agreement is also stated. We have followed a similar process, with the agreement leading to some improvements to the coding software.

Table 7 shows the reliability of the coding of the year of birth, the decision of the court, and the legal basis, both before and after making the improvements. The manual coding corresponds well with the coding of all variables by the program.

In the technical literature, it is common to state the accuracy of the coding. In the social science literature, Cohen's kappa is preferred, because in this metric the accuracy is corrected for chance hits. We give both metrics, as well as the number of true/false positives/negatives. (In case the number of true negatives is 0 , kappa cannot be calculated.)

The main issues with the coding software found as a result of the reliability study are:

- The age of the offenders was sometimes stated in words instead of numbers.

- Several laws were missing, and there were some problems with article numbers so that the legal basis was sometimes incompletely coded.

- A rarely used type of court decision was missing and the decision was sometimes incomplete.

The coding software has been improved so that these three issues are resolved.

Table 7 Reliability of the coding $(N=275)$

\begin{tabular}{|c|c|c|c|c|c|c|}
\hline Variable & Accuracy & Kappa & $\mathrm{TP}$ & FP & $\mathrm{FN}$ & $\mathrm{TN}$ \\
\hline Year of birth & 0.99 & 0.96 & 197 & 0 & 4 & 74 \\
\hline Legal basis & 0.88 & 0.67 & 195 & 31 & 2 & 47 \\
\hline Court decision & 0.99 & & 271 & 3 & 1 & 0 \\
\hline \multicolumn{7}{|c|}{ Reliability after improvements } \\
\hline Year of birth & 1.00 & 0.99 & 200 & 0 & 1 & 74 \\
\hline Legal basis & 0.95 & 0.84 & 214 & 12 & 2 & 47 \\
\hline Court decision & 0.99 & & 273 & 1 & 1 & 0 \\
\hline
\end{tabular}




\section{Case Study: Discussion}

Interpretation of the Results In related work, voluntary sentencing guidelines (Ulmer \& Johnson, 2004) and mandatory presumptive sentences (Engen \& Gainey, 2000) play an important role in harmonizing the sentence length. However, guidelines have a relatively small impact on sentence length in the models. One explanation could be that the guidelines are not mandatory; another could be that there are no guidelines for all crimes.

The average custodial sentence of the case study is about twice as long (24.8 months) as in the related work based on the Dutch data (see Table 1). There are two possible explanations. Firstly, we have included suspended sentences where others usually focus on the unsuspended part of the sentence (van Wingerden et al., 2016; Wermink et al., 2017). Secondly the offences present in the open dataset are more serious cases than those studied by, for example, van Wingerden et al. (2016).

Like van Wingerden et al. (2016), we found that the oldest offenders receive longer sentences. This can be explained by observing that an older offender is more likely to be a repeat offender and that a younger offender is usually treated more leniently.

There is a big gap between the maximum sentence and the actual sentence length, because the maximum punishment is reserved for the most heinous forms of crime in that category. To illustrate this, we give a few examples:

- Human trafficking (273f Penal code) has a maximum of 30 years, but an employee of a swingers club was sentenced to a prison sentence of 1 day for neglecting to verify the age of a minor visitor (ECLI:NL:RBOVE:2015:5781).

- Assault (302 Penal code) carries a maximum of 10 years, but a student was sentenced to 31 days in prison for assault during hazing (ECLI:NL:RBNNE:2017:4461).

- Possession of certain illegal narcotics (articles 2 and 10 Opium Act) carries a maximum sentence of 6 years imprisonment, but an offender who threw 4.2 g of MDMA over the walls of a prison was sentenced to 1 week detention (ECLI:NL:RBROT:2017:6082).

A large gap between maximum sentence and actual sentence creates outliers in the regression, which reduces the power of the analysis.

In contrast to the results of van Wingerden et al. (2016), the sex of the offender is not significant. The percentage of women in the case study $(8 \%)$ is even lower than in van Wingerden et al. (2016) (10\%). Women are underrepresented in serious crimes (Daly \& Tonry, 1997), and there may be too few women in our dataset to achieve a statistically significant result.

Contribution to the Theory The results show that offenders in a high-tech case receive a more severe sentence than offenders in a low-tech case. An explanation could be that offenders with special skills are more likely to commit large-scale offences; i.e. the offender uses ICT as a "crime multiplier". A large-scale offence is probably more serious than a small-scale offence, and as a result, the court imposes a longer sentence. We searched the dataset for court judgements with the word large-scale $(N=1517)$. The word occurs in $30.8 \%$ of the court judgements against an offender with special skills, and in $5.8 \%$ of the court judgements against an offender without special skills. This difference in frequencies is statistically significant $\left(\chi^{2}(1)=1039.0, p<0.0005\right)$. We give three examples of offences where ICT is used as a crime multiplier.

Drugs The street dealer must devote considerable time and effort to maintaining a relationship with his customers without attracting the attention of the police. By contrast, the 
vendor on a darknet marketplace does not have to spend time and effort to avoid raising suspicion because the technology (the TOR network and Bitcoin) does that for him. The technology not only makes it difficult for police to get a grip on the vendor, but it also makes a large-scale and global approach to drug trade easy (Christin, 2013).

CSA Not long ago, offenders of child sexual abuse had to rely on physical media. With the advent of the Internet, it became possible to collect and share media on a large scale, whereby the technology ensures anonymity and scalability (van der Bruggen \& Blokland, 2021).

Fraud Online banking is not only cost-effective for banks but also for fraudsters. With a large-scale and inexpensive phishing campaign, an offender can reach millions of potential victims. In this scenario, the offender only uses technology to achieve scalability. To avoid detection, he uses money mules (Leukfeldt, 2014).

In each of these examples, offenders use ICT as a crime multiplier to increase the scale of the offence. This not only makes offenders with special skills more blameworthy (because they make more victims), it also makes offenders with special skills more dangerous (because if they re-offend, they have the skills to do so on a large scale). The explanation, therefore, of the main result of the case study is that special ICT skills is a factor for two out of three focal concerns. Future research is needed to validate this refinement of focal concerns theory.

Limitations The published court judgements from the Open data of rechtspraak.nl relate to serious crimes. Therefore, our results are not representative of the total population of criminal court judgements.

The automatic coding of court judgements can lead to incorrect or missing coding. We manually checked a stratified random sample to estimate the error margins, which are small but not zero.

Most researchers have full control over the selection of cases they want to analyse. Because only a fraction of the court judgements are available as open data, we had less control over the selection.

\section{Conclusions and Policy Recommendations}

Transparency promotes confidence in the judiciary. Because open data promotes transparency, many countries make judicial documentation publicly available as open data. Since open data and sentencing research are both aimed at transparency, it is interesting to investigate sentencing severity using open data.

Research Questions We answer the first question "To what extent are the limitations of open data a barrier to obtaining good results?" by performing a case study. The open data comes from the Dutch criminal justice system Rechtspraak.nl. We analysed 25,366 court judgements from the period 2015-2020 and in particular, examined the relationship between the severity of the sentence and a range of predictors. The main result is that the quality of sentencing research with open data is comparable to the quality of sentencing research on richer data.

The answer to the research question is thus a qualified yes, in the sense that the variance explained by the linear regression model of the case study is $39 \%$, whereas comparable related work reports $60 \%$ (van Wingerden et al., 2016). We consider this a good result 
because we had no control over the selection of the court judgements, and because we have coded strictly less information per case. By way of future work we suggest to code whether a sentence has been suspended, and to code more information about the person of the offender (employment, accommodation, education, relationships, alcohol and drugs abuse, etc.).

The second research question "To what extent do offenders in high-tech cases receive a more severe sentence than offenders in low-tech cases?" has been investigated in the case study. We found that offenders who use advanced ICT are sentenced to significantly longer custodial sentences compared to other offenders. A possible explanation could be that ICT can be used as a crime multiplier, thus making an offender in high-tech cases both more blameworthy and more dangerous given the misuse of their technical skills. Future research is needed to investigate this hypothesis. We propose to include technical skills as one of the factors that determine blameworthiness and dangerousness in focal concerns theory.

As a practical application of our work, the encoding that our software calculates from a judgement could be added to a published judgement as extra metadata. By searching in this extra metadata, users of published judgements will be able to find the information they are looking for more quickly.

Court judgements are closely tied to a specific legal system and language so in principle the method that we have followed can be applied to other countries, but the coding software will probably have to be completely redeveloped.

European Policy Implications We make seven policy recommendations for improving judicial open data, which we hope will eventually be implemented in a European context (van Opijnen et al., 2017).

1. Judicial decisions are structured, but this structure is not strictly enforced (Trompper \& Winkels, 2016). Natural language offers possibilities to vary even standard structures. Annex I of the most recent European Council conclusions (Council of the EU, 2019) recommends a minimal structure for judgements that already represents a significant improvement over the status quo, but the recommendations can still be refined. For example, the facts about the suspect and the victims could be better separated so as not to confuse facts about the two in an analysis.

2. Published judgements are written for the human reader and not for statistical analysis. We recommend to add a minimal set of metadata that is representative of current research.

3. As long as only a subset of judgements issued by a court are published, the published judgements may give a distorted picture of crime. To prevent this, either a random selection of the judgements should be published, or the specific reasons for publication could be added as metadata to the publication.

4. Often, only the judgement is published and not the rest of the case file. Some European countries have started to publish more than just the judgement. We recommend this to become common practice, like in countries such as the USA.

5. To guarantee the integrity and authenticity of published judgements, we recommend that the responsible authority signs every judgement digitally.

6. We found 40 errors in the published court decisions and reported them to the appropriate authorities. We recommend keeping a list of errata per published judgement. This makes it possible to revise earlier analyses based on incorrect information later.

7. The transparency of the judiciary is promoted by the publication of judgements, but it is also the information obtained from scientific analyses that promotes transparency. 
We recommend creating and curating a collection of scientific articles that analyse the published judgements.

Supplementary Information The online version contains supplementary material available at https://doi.org/10.1007/s10610-021-09503-5.

Acknowledgements We thank Marianne Junger, Marc van Opijnen, Mortaza Shoae Barg, Frank van Tulder, and the anonymous referees for their comments on the paper

Data Availability The full dataset is available as open data from: rechtspraak.nl

Code Availability The coding software that we developed for this paper is available from https://doi.org/10.5281/zenodo.4773546.

Declarations The research complies with ethical standards because all data that has been analysed is open data that has been made public for analysis by third parties.

Conflict of Interest The authors declare no competing interests.

Open Access This article is licensed under a Creative Commons Attribution 4.0 International License, which permits use, sharing, adaptation, distribution and reproduction in any medium or format, as long as you give appropriate credit to the original author(s) and the source, provide a link to the Creative Commons licence, and indicate if changes were made. The images or other third party material in this article are included in the article's Creative Commons licence, unless indicated otherwise in a credit line to the material. If material is not included in the article's Creative Commons licence and your intended use is not permitted by statutory regulation or exceeds the permitted use, you will need to obtain permission directly from the copyright holder. To view a copy of this licence, visit http://creativecommons.org/licenses/by/4.0/.

\section{References}

Bargh, M. S., Choenni, S., \& Meijer, R.F. (2017). Integrating semi-open data in a criminal judicial setting. In Achieving Open Justice through Citizen Participation and Transparency, pages 137-156. IGI Global. https://doi.org/10.4018/978-1-5225-0717-8.ch007.

Berdejó, C., \& Yuchtman, N. (2013). Crime, punishment, and politics: an analysis of political cycles in criminal sentencing. Review of Economics and Statistics, 95(3), 741-756. https://doi.org/10.1162/REST_a_ 00296.

Bijlenga, N., \& Kleemans, E. R. (2018). Criminals seeking ICT-expertise: an exploratory study of Dutch cases. European J. on Criminal Policy and Research, 24, 253-268. https://doi.org/10.1007/s10610-0179356-Z.

Cao, Y., Ash, E., \& Chen, D.L. (2020). Automated fact-value distinction in court opinions. Eur J Law Econ, 50, 451-467. https://doi.org/10.1007/s10657-020-09645-7.

Christin, N. (2013). Traveling the Silk Road: A measurement analysis of a large anonymous online marketplace. In Int. Conf. on World Wide Web (WWW), pages 213-224, Rio de Janeiro, Brazil. ACM, New York. https://doi.org/10.1145/2488388.2488408.

Cohen, A., \& Yang, C. S. (2019). Judicial politics and sentencing decisions. American Economic J.: Economic Policy, 11(1), 160-191. https://doi.org/10.1257/pol.20170329.

Connolly, L. Y., \& Wall, D. S. (2019). The rise of crypto-ransomware in a changing cybercrime landscape: Taxonomising countermeasures. Computers \& Security, 87, 1-18. https://doi.org/10.1016/j.cose.2019. 101568.

Council of the EU (2019). Council conclusions on the european case law identifier (ecli) and a minimum set of uniform metadata for case law. Official Journal of the European Union, 62(C360), 1-22. https:// eur-lex.europa.eu/legal-content/EN/TXT/?uri=uriserv:OJ.C_.2019.360.01.0001.01.ENG.

Crow, M. S., \& Bales, W. (2006). Sentencing guidelines and focal concerns: the effect of sentencing policy as a practical constraint on sentencing decisions. American J. of Criminal Justice, 30(2), 285-304. https://doi.org/10.1007/BF02885896. 
Daly, K., \& Tonry, M. (1997). Gender, race, and sentencing. Crime and Justice, 22, $201-252$. https://doi.org/10.1086/449263.

de Jong, R., \& Dennison, S. (2017). Recorded offending among child sexual abuse victims: a 30-year followup. Child Abuse \& Neglect, 72, 75-84. https://doi.org/10.1016/j.chiabu.2017.07.013.

Engen, R. L., \& Gainey, R. R. (2000). Modeling the effects of legally relevant and extralegal factors under sentencing guidelines: the rules have changed. Criminology, 38(4), 1207-1230. https://doi.org/10.1111/ j.1745-9125.2000.tb01419.x.

Feldmeyer, B., \& Ulmer, J. T. (2011). Racial/ethnic threat and federal sentencing. J. of Research in Crime and Delinquency, 48(2), 238-270. https://doi.org/10.1177/0022427810391538.

Felson, M., \& Eckert, M. (2019). Crime and everyday life, sixth edition. London: Sage publishing.

Hadzhidimova, L. I., \& Payne, B. K. (2019). The profile of the international cyber offender in the U.S. Int. J. of Cybersecurity Intelligence \& Cybercrime, 2(1), 40-55. https://vc.bridgew.edu/ijcic/vol2/iss1/4.

Hartley, R. D. (2014). Focal concerns theory. In The Encyclopedia of Theoretical Criminology, pages 1-5. Blackwell Publishing. https://doi.org/10.1002/9781118517390.wbetc148.

Hester, R., \& Hartman, T. K. (2017). Conditional race disparities in criminal sentencing: a test of the liberation hypothesis from a non-guidelines state. J. of quantitative criminology, 33, 77-100. https://doi.org/10.1007/s10940-016-9283-z.

Huang, K.-C., Chen, K.-P., \& Lin, C.-C. (2010). Does the type of criminal defense counsel affect case outcomes?: A natural experiment in Taiwan. Int. Review of Law and Economics, 30(2), 113-127. https://doi.org/10.1016/j.irle.2009.09.005.

Kahneman, D. (2011). Thinking, Fast and Slow. Penguin.

Leukfeldt, E. R. (2014). Cybercrime and social ties - phishing in amsterdam. Trends in Organized Crime, 17(4), 231-249. https://doi.org/10.1007/s12117-014-9229-5.

Light, M. T., \& Wermink, H. (2021). The criminal case processing of foreign nationals in the Netherlands. Eur Sociol Rev, 37(1), 104-120. https://doi.org/10.1093/esr/jcaa039.

LOVS (2020). Oriëntatiepunten voor straftoemeting en lovs-afspraken. Technical report, Landelijk Overleg Vakinhoud Strafrecht. https://www.rechtspraak.nl/SiteCollectionDocuments/ Orientatiepunten-en-afspraken-LOVS.pdf.

Maddan, S., Hartley, R. D., Walker, J. T., \& Miller, J.M. (2012). Sympathy for the devil: an exploration of federal judicial discretion in the processing of white-collar offenders. American J. of Criminal Justice, 37, 4-18. https://doi.org/10.1007/s12103-010-9094-y.

Meijer, R. F., Moolenaar, D. E. G., Choenni, S., \& van den Braak, S.W. (2021). Criminaliteit en rechtshandhaving 2020 ontwikkelingen en samenhangen. Cahier 2021-22, Wetenschappelijk Onderzoek- en Documentatiecentrum (WODC). https://repository.wodc.nl/handle/20.500.12832/254.

Montoya, L., Junger, M., \& Hartel, P. (2013). How 'digital' is traditional crime? In European Intelligence and Security Informatics Conference, pages 31-37, Uppsala, Sweden. IEEE. https://doi.org/10.1109/EISIC.2013.12.

Patrick, S., \& Marsh, R. (2011). Sentencing outcomes of convicted child sex offenders. J. of child sexual abuse, 20(1), 94-108. https://doi.org/10.1080/10538712.2011.541356.

Peterson, J. L., Strom, K. J., \& Johnson, D.J. (2013). Effect of forensic evidence on criminal justice case processing. J. of forensic science, 58(S1), S78-S90. https://doi.org/10.1111/1556-4029.12020.

Pina-Sánchez, J., Grech, D., Brunton-Smith, I., \& Sferopoulos, D. (2019). Exploring the origin of sentencing disparities in the crown court: Using text mining techniques to differentiate between court and judge disparities. Social Science Research, 84(102371), 1-13. https://doi.org/10.1016/j.ssresearch.2019.102343.

Pina-Sánchez, J., \& Linacre, R. (2014). Enhancing consistency in sentencing: Exploring the effects of guidelines in England and Wales. J. of Quantitative Criminology, 30, 731-748. https://doi.org/10.1007/s10940-014-9221-x.

Raets, S., \& Janssens, J. (2021). Trafficking and technology: Exploring the role of digital communication technologies in the Belgian human trafficking business. European J. on Criminal Policy and Research, 27, 215-238. https://doi.org/10.1007/s10610-019-09429-z.

Rydberg, J., Cassidy, M., \& Socia, K.M. (2018). Punishing the wicked: Examining the correlates of sentence severity for convicted sex offenders. J. of quantitative criminology, 34, 943-970. https://doi.org/10.1007/s10940-017-9360-y.

Simon, H. A. (1955). A behavioral model of rational choice. The Quarterly J. of Economics, 69(1), 99-118. http://www.jstor.org/stable/1884852.

Spohn, C. C., Kim, B., Belenko, S., \& Brennan, P.K. (2014). The direct and indirect effects of offender drug use on federal sentencing outcomes. J. of quantitative Criminology, 30, 549-576. https://doi.org/10.1007/s10940-014-9214-9.

Trompper, M., \& Winkels, R. (2016). Automatic assignment of section structure to texts of Dutch court judgments. In Legal Knowledge and Information Systems: JURIX 2016: The Twenty- Ninth Annual 
Conference, volume Frontiers in Artificial Intelligence and Applications 294, pages 167-172, Sophia Antipolis, France. IOS Press, Amsterdam. https://doi.org/10.3233/978-1-61499-726-9-167.

Ulmer, J. T., \& Johnson, B. (2004). Sentencing in context: a multilevel analysis. Criminology, 42(1), 137178. https://doi.org/10.1111/j.1745-9125.2004.tb00516.x.

van den Berg, C., Bijleveld, C., \& Hendriks, J. (2017). The juvenile sex offender: Criminal careers and life events. Sex Abus, 29(1), 81-101. https://doi.org/10.1177/1079063215580967.

van den Hoven, P. (2011). Een strafrechtelijke uitspraak als tekstueel stelsel. Tijdschrift voor Taalbeheersing, 33(1), 5-15. https://doi.org/10.5117/TVT2011.1.EEN_397.

van der Bruggen, M., \& Blokland, A. (2021). A crime script analysis of child sexual exploitation material fora on the darkweb. Sexual abuse, Online first. https://doi.org/10.1177/1079063220981063.

van Opijnen, M., Peruginelli, G., Kefali, E., \& Palmirani, M. (2017). Online publication of court decisions in the eu. Leg Inf Manag, 17(3), 136-145. https://doi.org/10.1017/S1472669617000299.

van Wingerden, S., van Wilsem, J., \& Johnson, B.D. (2016). Offender's personal circumstances and punishment: Toward a more refined model for the explanation of sentencing disparities. Justice $Q, 33(1)$, 100-133. https://doi.org/10.1080/07418825.2014.902091.

Wermink, H., Johnson, B. D., de Keijser, J. W., Dirkzwager, A. J. E., Reef, J., \& Nieuwbeerta, P. (2017). The influence of detailed offender characteristics on consecutive criminal processing decisions in the Netherlands. Crime \& Delinquency, 63(10), 1279-1313. https://doi.org/10.1177/0011128715624929.

Wermink, H., Johnson, B. D., Nieuwbeerta, P., \& de Keijser, J.W. (2015). Expanding the scope of sentencing research: Determinants of juvenile and adult punishment in the Netherlands. Eur J Criminol, 12(6), 739-768. https://doi.org/10.1177/1477370815597253.

Publisher's Note Springer Nature remains neutral with regard to jurisdictional claims in published maps and institutional affiliations. 